\title{
Concentração e redistribuição de nutrientes minerais nos diferentes estádios foliares de seringueira
}

\author{
Aretusa Daniela Resende MENDES ${ }^{1}$, Luiz Edson Mota de OLIVEIRA², Marilza Neves do NASCIMENTO³, \\ Karina Lima REIS ${ }^{4}$, Lisandro Tomas da Silva BONOME5
}

\begin{abstract}
RESUMO
A seringueira na fase adulta possui um crescimento intermitente com o processo de troca de folhas, que é caracterizado pela senescência. Esse é um mecanismo que as árvores utilizam para reciclarem os nutrientes, por meio dos ciclos bioquímico e biogeoquímico. Estudos sobre o ciclo bioquímico sáo necessários para verificar o comportamento dos nutrientes minerais, nos diferentes estádios foliares, pois a conservação desses é importante, visto que os seringais são implantados em solos de baixa fertilidade. Desse modo, este trabalho teve por objetivo avaliar a dinâmica dos nutrientes minerais, durante os diferentes estádios foliares da seringueira. As folhas utilizadas foram provenientes de plantas do clone RRIM-600, de um seringal localizado em Nepomuceno, MG. Foram selecionadas oito árvores adultas que possuíam folhas nos diferentes estádios (B1, B2, C e D) e as senescentes (Sen.). As folhas nos estádios B1, B2, C e D foram coletadas nos quatro pontos ortogonais e as senescentes foram coletadas no solo após a agitação mecânica dos galhos. Observou-se que os nutrientes N, P, K, S, Cu e Zn diminuíram os seus teores nos diferentes estádios foliares da seringueira. No entanto, para $\mathrm{Ca}, \mathrm{Mg}, \mathrm{B}, \mathrm{Fe}$ e $\mathrm{Mn}$, verificarou-se um comportamento inverso. A redistribuição dos nutrientes foi maior para N, P, Ke Cu. A ordem relativa dos teores de macronutrientes encontrados nas folhas foi: $\mathrm{N}>\mathrm{K}>\mathrm{Ca}>\mathrm{Mg} \geq \mathrm{S}>\mathrm{P}$ e, para os micronutrientes, a ordem foi: $\mathrm{Mn}>\mathrm{Fe}>\mathrm{Zn}>\mathrm{B}>\mathrm{Cu}$.
\end{abstract}

PALAVRAS-CHAVE: Hevea brasiliensis. Ciclagem de nutrientes. Redistribuição de nutriente. Desenvolvimento foliar. Nutrição de plantas.

\section{Concentration and redistribution of mineral nutrients at different stages in the development of the Rubber tree leaf.}

\section{ABSTRACT}

The Rubber tree during its adult phase presents intermittent growth within the leaf exchange process characterized by senescence, which is a nutrient-recycling mechanism used by trees through biochemical and biogeochemical cycles. Studies including biochemical cycles are necessary in order to verify the mineral nutrients' dynamics at different leaf stages. The conservation of such nutrients is very important to optimize the growing conditions for rubber plantations which are located in soils with low fertility. This study aims to evaluate the mineral nutrients' dynamics during different leaf stages of the rubber tree, leaves were collected from the clones of RRIM-600 taken from a rubber tree plantation in Nepomuceno County, State of Minas Gerais, Brazil. Eight adult examples with leaves in different stages: B1, B2, C and D, plus senescent leaves (Sen) were selected for the study. Samples from leaves in stages B1, B2, C and D were taken from the trees at the four orthogonal points; the senescent leaves were collected from the ground after mechanically shaking the branches. The study revealed a decrease in the level of $\mathrm{N}, \mathrm{P}, \mathrm{K}, \mathrm{S}, \mathrm{Cu}$ and $\mathrm{Zn}$ during the development of the rubber tree's leaf. In contrast, during the same period the levels of Ca, $\mathrm{Mg}, \mathrm{B}, \mathrm{Fe}$ and $\mathrm{Mn}$ increased. The redistribution for $\mathrm{N}, \mathrm{P}, \mathrm{K}$ and $\mathrm{Cu}$ was higher and the relative order of macronutrient and micronutrient levels in the leaves were respectively: $\mathrm{N}>\mathrm{K}>\mathrm{Ca}>\mathrm{Mg} \geq \mathrm{S}>\mathrm{P}$ and $\mathrm{Mn}>\mathrm{Fe}>\mathrm{Zn}>\mathrm{B}>\mathrm{Cu}$

KEYWORDS: Hevea brasiliensis. Nutrient cycling. Nutrient redistribution. Leaf development. Plant nutrition.

\footnotetext{
(1) Universidade Federal de Minas Gerais/Instituto de Ciências Agrárias - Avenida Universitária, 1.000 - Bairro Universitário - Montes Claros-MG - CEP: 39.404-006 - are.dani@hotmail.com; (2) Universidade Federal de Lavras/Departamento de Biologia - Campus Universitário, Caixa Postal 3037 - Lavras-MG - CEP: 37200-000, ledson@dbi.ufla.br;

(3) Universidade Estadual de Feira de Santana - Avenida Transnordestina, S/N - Bairro Novo Horizonte - Feira de Santana-BA - CEP: 44.036-900, marilzaagro@hotmail.com;

(4) Universidade de São Paulo/Escola Superior de Agricultura Luiz de Queiroz/Programa de pós-graduação em Fisiologia e Bioquímicas de Plantas - Avenida Pádua Dias, 11 - Bairro Vila Independência - Piracicaba-SP - CEP: 13418-900, kakalmed@hotmail.com;

(5) Universidade Federal da Fronteira do Sul - Avenida Oscar da Silva Guedes, 01 - Bairro Vila Alberti - Laranjeiras do Sul-PR - CEP: 85303-820, lisandrobonome@gmail.com.
} 


\section{INTRODUÇÃO}

Há muito, a heveicultura desperta interesse, devido ao seu potencial de utilizaçáo, que proporciona benefícios econômicos, sociais e ambientais. No Brasil, o cultivo de seringueira vem expandindo-se e ocupando diversas regióes, principalmente as com solo de baixa fertilidade. Com isso, exige-se o desenvolvimento de tecnologias mais apropriadas para o seu cultivo. Dentro dessas áreas de expansão do Brasil, as regiōes Sudeste e Centro-Oeste destacam-se por apresentarem áreas aptas à heveicultura. Segundo Pilau et al. (2007), a regiáo Sudeste possui a maior parte do território, 738.696 $\mathrm{km}^{2}$, atendendo, plenamente, às exigências térmicas e hídricas da cultura. Nessas áreas, a ocorrência da temperatura mínina entre $15^{\circ} \mathrm{C}$ e $21^{\circ} \mathrm{C}$ impede a esporulação do fungo causador do "mal-das-folhas", evitando que haja infecção da brotação de primavera pelo baixo potencial de inóculo.

$\mathrm{Na}$ região Sudeste, Sáo Paulo destaca-se como o maior produtor de borracha natural e com um número significativo de usinas de beneficiamento de borracha do país. Outro estado que vem se destacando para a expansão da heveicultura é Minas Gerais, devido à sua proximidade com Sáo Paulo e também por apresentar condições térmicas e hídricas satisfatórias ao desenvolvimento da cultura (Gonçalves et al. 2001; Pilau et al. 2007). No entanto, a heveicultura ainda é incipiente em Minas Gerais, principalmente na regiáo sul e, para que a expansão e o fortalecimento da heveicultura sejam bem sucedidos, é necessário, entre outras iniciativas, o aprofundamento de estudos associados a fatores que influenciam a produção de látex.

O conhecimento do estado nutricional é um requisito básico para a recomendação adequada de fertilizantes, com vistas a suprir a exigência da cultura e, consequentemente, a obter-se produtividade elevada de látex (Murbach et al. 2003). As raízes da seringueira exploram os nutrientes do solo, utilizando-os na formação de fitomassa e grande parte retorna à planta, durante o processo de senescência e ao solo com a queda das folhas e ramos, formando uma densa camada de serrapilheira que, posteriormente, se decompõe (Virgens Filho et al. 2003). A avaliaçáo tanto de solos como de folhas tem servido de base para a discriminação de adubação e a diagnose foliar vem sendo bastante útil a esse manejo, uma vez que as folhas refletem melhor o estado nutricional (Malavolta et al. 1997).

A variaçấo dos teores de nutrientes minerais nas folhas depende de fatores bióticos e abióticos; entre eles, pragas e doenças, idade das árvores e das folhas, posição na copa, estação do ano, disponibilidade do nutriente no solo e características nutricionais de cada espécie (Caldeira et al. 1999). A idade da folha merece destaque, por afetar a distribuição e a redistribuição dos nutrientes, por meio dos ciclos bioquímico (redistribuição interna) e biogeoquímico.
Os ciclos da ontogenia foliar de plantas de seringueira compreendem quatro estádios: A, B, C e D, relacionados ao nível de atividade do meristema apical e às fases de desenvolvimento foliar (Hallé et al. 1978). Nas regiôes Sudeste e Centro-Oeste do Brasil, a seringueira apresenta um crescimento intermitente com o processo de troca de folhas, que é caracterizado pela senescência (Murbach et al. 2003). Esse comportamento decíduo depende da constituição genética, da intensidade, da duração do déficit hídrico na estação seca e, também, das condiçóes de nutrição mineral (Bataglia et al. 1999).

Os fluxos de nutrientes internamente são controlados por mecanismos de conservaçáo de nutrientes. Esses são mais acentuados em plantas implantadas em solos de baixa fertilidade (Caldeira et al. 1999; Silva et al. 1998). A redistribuição interna de nutrientes nos tecidos é um aspecto importante da economia de nutrientes em plantas perenes, com grande influência sobre o ecossistema (Lusk et al. 2003). Provavelmente, a redistribuição dos nutrientes em folhas de seringueira nas regiôes de expansão da heveicultura é intensa, pois essas apresentam solos de fertilidade marginais.

Silva et al. (1998), avaliando a redistribuição de nutrientes minerais em três estádios foliares de seringueira, verificaram que os teores foliares de $\mathrm{N}$, de $\mathrm{P}$, de $\mathrm{K}$ e de Mg diminuíram, com o aumento da idade da folha. Por outro lado, os teores de Ca aumentaram com a idade da folha, apresentando teores significativamente inferiores nas folhas jovens, por ser imóvel na planta. Os teores de $S$ não apresentaram um padrão de variação definido. Resultados semelhantes foram observados por Rodrigues et al. (2000), que concluíram que a redistribuição de $\mathrm{N}$, de $\mathrm{P}$ e de $\mathrm{K}$ desempenha um papel importante na nutrição da seringueira. Esses trabalhos não estudaram o comportamento dos nutrientes em todos os estádios foliares, implicando, assim, na necessidade de mais investigaçóes para o conhecimento da nutrição mineral das folhas da seringueira.

A presente pesquisa foi conduzida com o objetivo de avaliar a concentração dos nutrientes durante os estádios foliares da Hevea brasiliensis, bem como de verificar a redistribuição desses nutrientes das folhas senescentes.

\section{MATERIAL E MÉTODOS}

O povoamento estudado de Hevea brasiliensis localiza-se no município de Nepomuceno, no sul de Minas Gerais. As coordenadas geográficas de referência são $21^{\circ} 17^{\prime} 33^{\prime \prime} \mathrm{S}$ de latitude, $45^{\circ} 10^{\prime} 41^{\prime \prime} \mathrm{W}$ de longitude e $904 \mathrm{~m}$ de altitude. O clima do município é do tipo CWB, segundo a classificação de Köppen (mesotérmico com verôes brandos e suaves e estiagem de inverno). A vegetaçáo anterior à implantação dos seringais era de mata nativa. 
O seringal foi implantado em 2005 . O clone utilizado foi o RRIM-600, com espaçamento de $3 \mathrm{~m} \times 7 \mathrm{~m}$. No momento da coleta das folhas, o seringal encontrava-se com cinco anos de idade, sem sangria, com altura de 4,0 a $6,5 \mathrm{~m}$ e o perímetro médio de $0,4 \mathrm{~m}$ à altura de $1,50 \mathrm{~m}$ do solo (DAP). O solo é do tipo Argissolo Vermelho-Amarelo, de textura argilosa, apresentando as seguintes características químicas na profundidade de 0,0-0,2 $\mathrm{m}$ (Tabela1). As características químicas do solo foram determinadas de acordo com a metodologia preconizada pela Empresa Brasileira de Pesquisa Agropecuária - EMBRAPA (1999).

Dentro do seringal, foram selecionadas oito árvores adultas que apresentavam $5,0 \mathrm{~m}$ de altura, o perímetro de $0,4 \mathrm{~m}$ à altura de $1,50 \mathrm{~m}$ do solo (DAP) e que possuíam folhas nos diferentes estádios (B1, B2, C e D) e senescentes (Sen.). As identificaçóes desses estádios fenológicos foram feitas, baseando-se na caracterização e descrição de Hallé et al. (1978).

As folhas nos estádios B1, B2, C e D foram coletadas com o auxílio de um podáo nos quatro pontos ortogonais, sendo cinco folhas em cada ponto, na parte mediana da copa da árvore. As folhas senescentes foram coletadas no chão. Para garantir que as folhas pertenciam às árvores selecionadas, a área da projeçấo da copa de cada árvore foi limpa, retirandose galhos e folhas existentes. Posteriormente, os galhos da árvore foram agitados mecanicamente até a queda das folhas senescentes, as quais foram imediatamente coletadas. $\mathrm{O}$ horário de coleta das folhas foi de 08:00 às 10:00 horas.

Após a coleta, as folhas de cada estádio de desenvolvimento foram lavadas e secas em estufa de circulaçáo forçada de ar a $60^{\circ} \mathrm{C} \pm 5{ }^{\circ} \mathrm{C}$ até atingir peso constante. As folhas secas de cada estádio foliar foram moídas em moinho tipo Willey com malha de 20 mesh.

Após a moagem, os teores dos macronutrientes: N, P, K, $\mathrm{Ca}, \mathrm{Mg}$ e $\mathrm{S}$ e micronutrientes: $\mathrm{B}, \mathrm{Cu}, \mathrm{Fe}, \mathrm{Mn}$ e $\mathrm{Zn}$ foram determinados quimicamente de acordo com Malavolta et al. (1997).

As faixas dos teores considerados adequados às folhas maduras (estádio D) de seringueiras adultas para os macronutrientes e micronutrientes foram determinadas por diversos autores (Tabela 2).

Tabela 1 - Caracterização química de amostras de solo coletadas na camada de 0-20 cm

\begin{tabular}{|c|c|c|c|c|c|c|}
\hline \multirow{2}{*}{$\mathrm{pH}^{1}$} & $\mathrm{P}^{2}$ & $\mathrm{~K}^{2}$ & $\mathrm{Ca}^{2+}$ & $\mathrm{Mg}^{2+}$ & $\mathrm{Al}^{3+}$ & $\mathrm{H}+\mathrm{Al}$ \\
\hline & \multicolumn{2}{|c|}{ 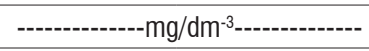 } & \multicolumn{4}{|c|}{ - } \\
\hline $4,41 \pm 0,05$ & $2,38 \pm 0,26$ & $62,25 \pm 8,42$ & $1,16 \pm 0,13$ & $0,45 \pm 0,05$ & $0,73 \pm 0,09$ & $5,25 \pm 0,2$ \\
\hline Ac. Muito elevada & MBX. & Méd. & Méd. & Méd. & Méd. & Alto \\
\hline $\mathrm{SO}_{4}^{-}$ & $\mathrm{B}^{3}$ & $\mathrm{Cu}^{2}$ & $\mathrm{Fe}^{2}$ & $\mathrm{Mn}^{2}$ & $\mathrm{Zn}^{2}$ & M. $0^{4}$ \\
\hline \multicolumn{6}{|c|}{ 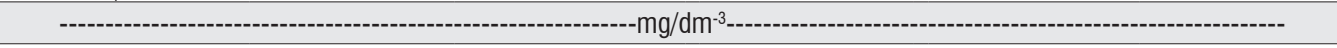 } & $\mathrm{dag} / \mathrm{kg}$ \\
\hline $7,03 \pm 0,30$ & $0,15 \pm 0,02$ & $2,00 \pm 0,07$ & $63,44 \pm 6,25$ & $20,51 \pm 0,71$ & $1,88 \pm 0,79$ & $1.9 \pm 0,08$ \\
\hline Méd. & Bx. & Alto & Alto & Alto & Bom & Bx. \\
\hline P-rem. & $t^{5}$ & $\mathrm{~T}^{6}$ & $\mathrm{SB}^{7}$ & $\mathrm{~V}^{8}$ & $\mathrm{~m}^{9}$ & \\
\hline $\mathrm{mg} / \mathrm{L}$ & \multicolumn{3}{|c|}{ - } & \multicolumn{2}{|c|}{-------------------_\%-------------- } & \\
\hline $21,19 \pm 0.8$ & $2,50 \pm 0,14$ & $7,03 \pm 0,30$ & $1,78 \pm 0,19$ & $25,03 \pm 1,97$ & $30,03 \pm 4,28$ & \\
\hline & Méd. & Méd. & Méd. & Bx. & Méd. & \\
\hline
\end{tabular}

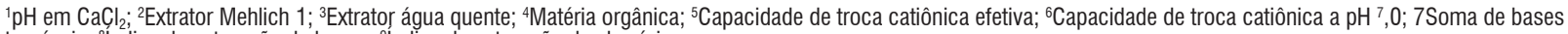
trocáveis; ' indice de saturação de bases; ' 9 ndice de saturação de alumínio

Tabela 2 - Valores de referência dos teores dos nutrientes para interpretação dos resultados de análises de tecidos foliares em seringueira adulta

\begin{tabular}{lcccc}
\hline \multirow{2}{*}{ Nutrientes minerais } & \multicolumn{3}{c}{ Autores } \\
\cline { 2 - 5 } & Cantarutti et al. (2007) & Garcia et al. (1999) & Malavolta et al. (1997) & Raij et al. (1997) \\
\hline Nitrogênio $\left(\mathrm{g} \mathrm{kg}^{-1}\right)$ & $26-35$ & $30-35$ & $26-35$ & $29-35$ \\
Fósforo $\left(\mathrm{g} \mathrm{kg}^{-1}\right)$ & $1,6-2,3$ & $2,0-2,5$ & $1,6-2,3$ & $1,6-2,5$ \\
Potássio $\left(\mathrm{g} \mathrm{kg}^{-1}\right)$ & $10-14$ & $12-15$ & $10-14$ & $10-17$ \\
Cálcio $\left(\mathrm{g} \mathrm{kg}^{-1}\right)$ & $10-14$ & $12-15$ & $7,6-8,2$ & $10-17$ \\
Magnésio $\left(\mathrm{g} \mathrm{kg}^{-1}\right)$ & $1,7-2,5$ & $2,4-4,0$ & $1,7-2,4$ & $1,7-2,5$ \\
Enxofre $\left(\mathrm{g} \mathrm{kg}^{-1}\right)$ & $1,8-2,6$ & $1,4-2,6$ & $1,8-2,6$ & $1,8-2,6$ \\
Boro $\left(\mathrm{mg} \mathrm{kg}^{-1}\right)$ & $20-70$ & $20-70$ & $20-70$ & $20-70$ \\
Cobre $\left(\mathrm{mg} \mathrm{kg}^{-1}\right)$ & $10-15$ & $10-30$ & $10-15$ & $10-15$ \\
Ferro $\left(\mathrm{mg} \mathrm{kg}^{-1}\right)$ & $70-90$ & $66-200$ & $70-90$ & $50-120$ \\
Manganês $\left(\mathrm{mg} \mathrm{kg}^{-1}\right)$ & $15-40$ & $40-200$ & $15-40$ & $40-150$ \\
Zinco $\left(\mathrm{mg} \mathrm{kg}^{-1}\right)$ & $20-30$ & $25-50$ & $20-30$ & $20-40$ \\
\hline
\end{tabular}


A redistribuiçáo dos nutrientes minerais foi calculada comparando-se os teores dos nutrientes na folha senescente com os teores nas folhas maduras (estádio D), de acordo com Attiwill et al. (1978):

Re distribuição $(\%)=\frac{\text { Teor dafolhasenescente-Teor da folhamadura }}{\text { Teorda folhamadura }} \times 100$

\section{RESULTADOS E DISCUSSÃO}

Nas condiçôes em que a pesquisa foi realizada, observou-se que a concentração média dos nutrientes em folhas maduras (estádio D) foi de 32,0 $\mathrm{g} \mathrm{kg}^{-1}$ de N, 1,6 $\mathrm{g} \mathrm{kg}^{-1}$ de P, 7,7 $\mathrm{g} \mathrm{kg}^{-1}$ de K, 16,0 $\mathrm{g} \mathrm{kg}^{-1}$ de Ca, 4,0 $\mathrm{g} \mathrm{kg}^{-1}$ de $\mathrm{Mg}$ e 3,6 $\mathrm{g} \mathrm{kg}^{-1}$ de $S$; 45,8 $\mathrm{mg} \mathrm{kg}^{-1}$ de B, 8,0 $\mathrm{mg} \mathrm{kg}^{-1}$ de Cu, 94,0 mg kg-1 de Fe, $343,0 \mathrm{mg} \mathrm{kg}^{-1}$ de Mn, 24,0 $\mathrm{mg} \mathrm{kg}^{-1}$ de Zn.

Os teores de N, de P, de B, de Fe e de Zn encontrados nesta pesquisa se enquadram dentro da faixa considerada adequada por Cantarutti et al. (2007), Garcia et al. (1999), Malavolta et al. (1997) e Raij et al. (1997). O Ca, o S e o Mn tiveram teores acima dos considerados adequados. $\mathrm{O} \mathrm{Mg}$ apresentou o seu teor adequado, segundo Garcia et al. (1999). No entanto, para os autores Raij et al. (1997), Malavolta et al. (1997) e Cantarutti et al. (2007), o teor encontrado de Mg está acima do adequado. $\mathrm{O} \mathrm{Ke} \mathrm{Cu}$ foram os nutrientes que apresentaram teores inferiores.

O baixo teor de $\mathrm{K}$ encontrado nas folhas maduras do seringal em estudo pode estar relacionado às características químicas do solo em que o seringal está implantado, com a acidez elevada e com a capacidade de troca catiônica efetiva média, o que favorece a lixiviação do $\mathrm{K}$, ocasionando a redução da disponibilidade do mesmo na soluçáo do solo próximo à zona radicular (Santos et al. 2002). Além disso, o $\mathrm{K}^{+}$compete com vários cátions pelos sítios de absorção na membrana

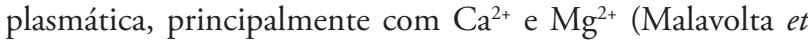
al. 1997). Assim, a menor absorção de potássio pelas plantas em estudo, possivelmente, se deve à baixa concentraçáo desse íon na solução do solo e à maior absorção dos cátions que competem pelo mesmo sítio de absorção. Bataglia et al. (1999), em seringais no período de imaturidade, verificaram que a interação entre os nutrientes $\mathrm{N}, \mathrm{P}$ e K dos fertilizantes aplicados correlacionou-se, negativamente, com os teores de

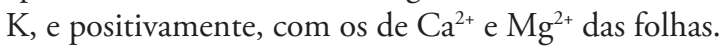

Os teores de $\mathrm{Ca}^{2+} \mathrm{e} \mathrm{Mg}^{2+}$ encontravam-se altos nas folhas maduras do seringal em estudo, mesmo sob as condiçóes de acidez do solo apresentando, assim, uma alta capacidade de absorção desses nutrientes. Esses resultados estão de acordo com Bataglia et al. (1988), os quais observaram que a disponibilidade de $\mathrm{Ca}$ e $\mathrm{Mg}$ às plantas não foi afetada pela acidez do solo.

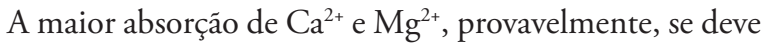
à maior exigência da cultura a esses nutrientes. $\mathrm{O}$ cálcio é um dos nutrientes mais exigidos pela seringueira, sobretudo na fase adulta, sendo esse nutriente associado à produtividade de borracha seca. Roque et al. (2004) verificaram que a aplicação de calcário superficialmente levou o teor de $\mathrm{Ca}^{2+}$ na folha de seringueira e esse esteve associado à elevada produtividade de borracha seca. Esse elemento possui importância especial no desenvolvimento da raiz, sendo um dos componentes da parede celular, além disso, é indispensável à mitose no processo de divisão celular (Reis e Chepote 2008). Já o magnésio é de extrema importância para a produtividade da cultura, uma vez que, é um elemento constituinte da molécula de clorofila e desempenha um papel indispensável no processo da fotossíntese, funcionando como ativador de várias enzimas relacionadas ao metabolismo dos carboidratos e outras envolvidas na síntese dos ácidos nucleicos (Reis e Chepote 2008).

$\mathrm{O}$ alto teor de $\mathrm{Mn}$ encontrado nas folhas, possivelmente, se deve à alta disponibilidade desse no solo, $20,5 \mathrm{mg} \mathrm{dm}^{-3}$. Segundo Malavolta et al. (1997), sob condiçóes de solo ácido, a disponibilidade de Mn é aumentada, devido à maior solubilidade dos compostos que o contêm, favorecendo, assim, a sua absorção.

$\mathrm{O}$ teor de $\mathrm{Cu}$ no solo do seringal encontra-se alto, no entanto o teor foliar apresentou abaixo do mínimo requerido por Cantarutti et al. (2007), Garcia et al. (1999), Malavolta et al. (1997) e Raij et al. (1997). Amarante et al. (2010), analisando a composição química folhas de aninga, admitem que os baixos teores de cobre obtidos podem estar relacionados ao excesso de manganês, devido a uma relação inversa entre o $\mathrm{Cu}$ e o Mn. Esse baixo teor de cobre na folha de seringueira também pode estar relacionado ao acúmulo deste nas raízes (Malavolta et al. 1997), parte náo analisada no presente estudo.

As concentraçóes dos macronutrientes nos diferentes estádios de desenvolvimento foliar da seringueira variaram em razão do estádio de desenvolvimento foliar (Figura 1).

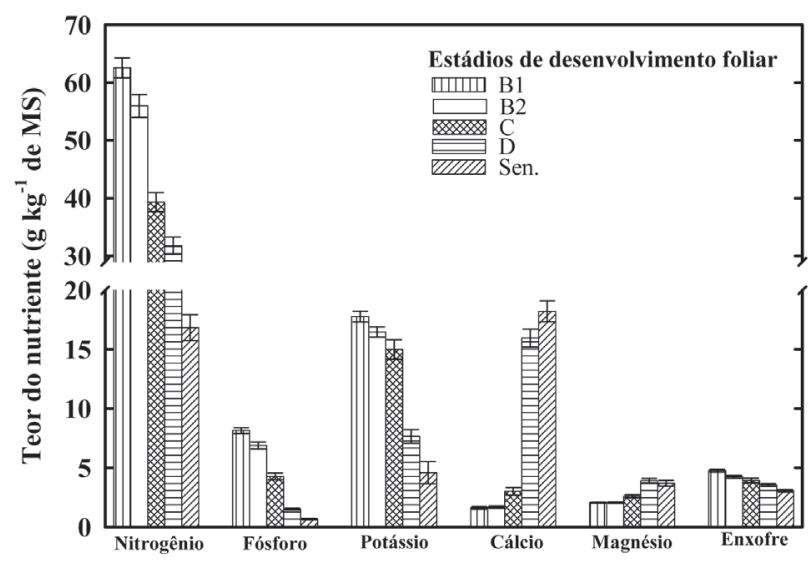

Figura 1 - Teores dos nutrientes: nitrogênio $(\mathrm{N})$, fósforo $(\mathrm{P})$, potássio $(\mathrm{K})$, cálcio (Ca), magnésio (Mg) e enxofre (S), em diferentes estádios de desenvolvimento foliar de seringueira (clone RRIM-600). As barras indicam o erro padrão da média de oito repetições 
Dentre os macronutrientes, o nitrogênio foi o elemento mais abundante nos diferentes estádios de desenvolvimento da folha de seringueira, exceto para o estádio senescente, em que o teor de cálcio superou o de nitrogênio.

Os teores de nitrogênio, de fósforo e de potássio reduziram significativamente com o avanço do desenvolvimento foliar (Figura 1). A redução nos teores de $\mathrm{N}$, de $\mathrm{P}$ e de $\mathrm{K}$ sugere uma redistribuição desses nutrientes das folhas fontes, do estádio $\mathrm{D}$ e das folhas senescentes, para regióes de crescimento da planta, evidenciando, dessa maneira a alta capacidade destes macronutrientes serem redistribuídos na seringueira. Essa redistribuiçáo dos nutrientes no interior da planta durante a senescência foliar é um processo fisiológico fundamental para a retençáo dos nutrientes no vegetal (Silva et al. 1998). De acordo com Piatek e Allen (2000), as fontes primárias de nutrientes nos tecidos foliares são oriundas da oferta do solo e da retranslocação de tecidos senescentes.

O teor do $\mathrm{Mg}$ aumentou a partir do estádio $\mathrm{C}$, não apresentando diferença significativa entre o estádio $\mathrm{D}$ e a folha senescente. Os íons de $\mathrm{Mg}$ têm papel fundamental no metabolismo da planta, pois, além de participar da constituição da molécula de clorofila, é o nutriente que mais atua na ativação enzimática, sendo co-fator de quase todas as enzimas fosforilativas, as quais são essenciais aos processos de respiração, fotossíntese e síntese de DNA e RNA (Malavolta et al. 1997). $\mathrm{O}$ aumento no teor de $\mathrm{Mg}$ pode ter ocorrido, devido ao fato de que, no estádio $\mathrm{C}$, as folhas se encontram pendentes, flácidas e com coloração verde clara, diferentemente das folhas no estádio $\mathrm{D}$, que se encontram totalmente expandidas e amadurecidas. Possivelmente, o aparato fotossintético das folhas no estádio $\mathrm{C}$ não se encontrava completamente desenvolvido, exigindo, portanto, menores teores de $\mathrm{Mg}$ do que as folhas no estádio D. Miguel et al. (2007), estudando o comportamento fotossintético durante a ontogenia foliar de clones de seringueira, verificaram que, a partir do $37^{\circ}$ dia de desenvolvimento foliar, início do estádio $\mathrm{C}$, os teores de clorofila a, b e total aumentaram, atingindo valores até três vezes maiores no $57^{\circ}$ dia (estádio D). Esses autores relataram ainda que no estádio $\mathrm{D}$ de desenvolvimento foliar, ocorre a maior atividade fotossintética liquida, eficiência fotoquímica do fotossistema II, eficiência de carboxilação, condutância estomática e transpiraçáo. Embora o Mg seja um elemento móvel na planta, a sua concentração aumenta com o envelhecimento das folhas, provavelmente, por ter várias funçóes na planta, atuando em todos os estádios de crescimento da folha.

À semelhança dos nutrientes $\mathrm{N}, \mathrm{P}$ e K, o enxofre teve o seu teor reduzido com o desenvolvimento foliar, apresentando maior teor no estádio B1 e o menor, na folha senescente (Figura 1), porém essa redução foi em menores proporçôes que a observada para o $\mathrm{N}$, o P e o K. O enxofre, além de ser um dos constituintes de aminoácidos, proteínas e de substâncias reguladoras de crescimento, como a biotina e a tiamina, desempenha um papel importante na estruturação de proteínas, por meio das ligaçóes de dissulfeto (Reis e Chepote 2008). Silva et al. (1998), investigando a translocaçáo de nutrientes em folhas de Hevea brasiliensis e em acículas de Pinus oocarpa, não encontraram um padrão definido de variação para o enxofre.

O nutriente cálcio apresentou um aumento significativo com o desenvolvimento foliar. Esse é um elemento estrutural, associado à lignificação das paredes celulares e, portanto, menos redistribuído na planta. Assim, a elevação nos teores de cálcio com o avanço da idade das folhas pode ser justificada pelo aumento na produção de constituintes estruturais da folha e pela baixa mobilidade desse elemento na planta (Caldeira $e t$ al. 2000; Vieira e Schumacher 2009).

Os teores dos micronutrientes (Figura 2) variaram em função dos estádios de desenvolvimento foliar, assim como os teores dos macronutrientes. $\mathrm{O}$ cobre e o zinco apresentaram uma redução significativa até o estádio $\mathrm{D}$ e esse estádio não diferiu da folha senescente. Resultado similar foi encontrado por Vieira e Schumacher (2009), em Pinus taeda.

Entre os micronutrientes, o $\mathrm{Cu}$ foi o que apresentou menor teor no desenvolvimento foliar da seringueira (Figura 2). Shorrocks (1965) constatou que o cobre é o micronutriente menos absorvido pela seringueira. Esta pesquisa corroborou o estudo de Shorrocks (1965), quanto ao teor de $\mathrm{Cu}$.

$\mathrm{O}$ ferro e manganês aumentaram seus teores com o desenvolvimento foliar apresentando maiores teores na folha senescente. Em conformidade com Shorrocks (1965), o ferro é o micronutriente mais absorvido, seguido do manganês. No entanto, nas condiçôes da presente pesquisa, o manganês apresentou o maior teor, possivelmente devido à sua maior disponibilidade no solo e à inibição da absorção do ferro. $\mathrm{O}$

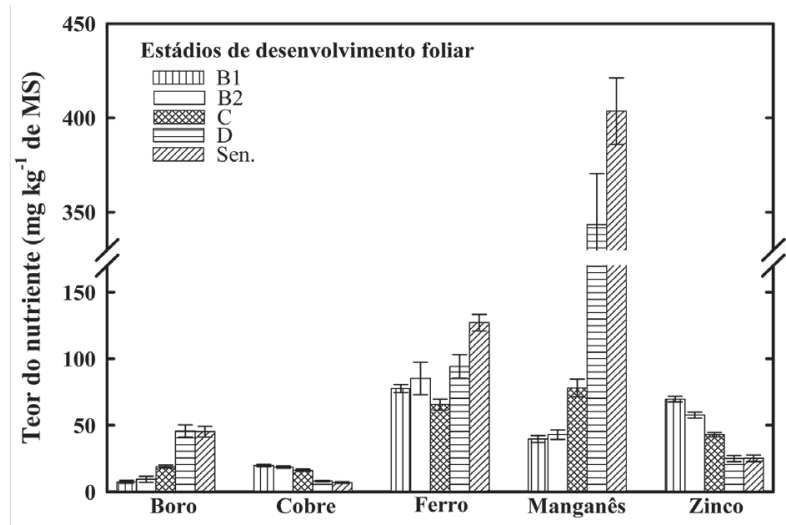

Figura 2 - Teores dos nutrientes: boro (B), cobre (Cu), ferro (Fe), manganês (Mn), e zinco (Zn), em diferentes estádios de desenvolvimento foliar em seringueira (clone RRIM-600). As barras indicam o erro padrão da média de oito repetições 
Fe tem um importante papel na ativaçáo de enzimas, atuando como grupo prostético. Participa em reaçóes de oxidorredução em hemoproteínas e proteínas não-hémicas com ligação $\mathrm{Fe}-\mathrm{S}$ e em ferrodoxina, enzimas redutase, nitrogenase e sulfato redutase. Além disso, catalisa a biossíntese da clorofila, uma vez que faz parte de enzimas responsáveis pela sua formação (Malavolta et al. 1997). O Mn é essencial à síntese de clorofila e atua na ativação de enzimas, tendo papel crucial no fotossistema II, sendo responsável pela fotólise da água (Malavolta et al. 1997). Magalhães e Blum (1999), avaliando a concentração e a distribuição de nutrientes nas folhas de espécies florestais, na Amazônia ocidental, constataram que, em todas as espécies estudadas, os teores de $\mathrm{Fe}$ e de $\mathrm{Mn}$ foram maiores em folhas maduras do que em folhas novas e senescentes, com exceção da espécie Gmelina arbórea, em que o teor de $\mathrm{Mn}$ foi maior em folhas jovens. Resultado semelhante foi observado por Vieira e Schumacher (2009), em Pinus taeda.

O boro apresentou um comportamento semelhante ao ferro e ao manganês, ou seja, um aumento com o desenvolvimento foliar. No entanto o teor de B no estádio D e nas folhas senescentes náo diferiu. $\mathrm{O}$ boro é um nutriente imóvel na planta, assim como o cálcio, portanto, o seu incremento com o desenvolvimento foliar pode ser justificado pela sua imobilidade.

A redistribuição dos nutrientes é apresentada na Tabela 3. Todos os macronutrientes foram redistribuídos das folhas senescentes para os órgãos em crescimento, exceção feita para o $\mathrm{Ca}$, o qual acumulou com o desenvolvimento foliar. O teor do Ca aumentou em 14,2\% em relação ao observado no estádio inicial de formação da folha, evidenciando, assim, a sua imobilidade na planta. Os macronutrientes mais redistribuídos nas folhas de seringueira foram: N, P e K. Esta pesquisa encontrou percentuais de redistribuição em seringueiras semelhantes aos encontrados por Rodrigues et al. (2000), os quais avaliaram as concentraçóes e a redistribuição de nutrientes em folhas em $H$. brasiliensis e $P$. oocarpa.

A redistribuição dos micronutrientes não apresentou um padrão bem definido em função do estádio de desenvolvimento foliar, exceto para o $\mathrm{Cu}$, que apresentou uma redistribuíição de $12,7 \%$ e para o $\mathrm{Fe}$ e $\mathrm{Mn}$, que acumularam $17,5 \%$ e $35,0 \%$, respectivamente, com o desenvolvimento foliar.

Tabela 3 - Redistribuição dos nutrientes (\%) nas folhas de seringueira (clone do RRIM-600)

\begin{tabular}{|c|c|c|c|c|c|c|c|c|c|c|}
\hline \multicolumn{11}{|c|}{ Redistribuição (\%) } \\
\hline $\mathrm{N}$ & $P$ & $K$ & $\mathrm{Ca}$ & $\mathrm{Mg}$ & $S$ & $B$ & $\mathrm{Cu}$ & $\mathrm{Fe}$ & $\mathrm{Mn}$ & $\mathrm{Zn}$ \\
\hline
\end{tabular}

A ordem relativa do teor de macronutrientes nas folhas maduras (estádio D) de seringueira encontrada na presente pesquisa foi: $\mathrm{N}>\mathrm{K}>\mathrm{Ca}>\mathrm{Mg} \geq \mathrm{S}>\mathrm{P}$. Esse resultado diverge dos encontrados por Shorrocks (1979), que apresentou a seguinte ordem: $\mathrm{N}>\mathrm{K}>\mathrm{Ca}>\mathrm{Mg}>\mathrm{P}>\mathrm{S}$ e por Rodrigues et al. (2000) e Silva et al. (1998), que apresentaram a ordem $\mathrm{K}>\mathrm{N}>\mathrm{Ca}>\mathrm{P}>\mathrm{S}>\mathrm{Mg}$. A ordem relativa do teor de micronutrientes nas folhas maduras (estádio D) de seringueira encontrada na presente pesquisa foi: $\mathrm{Mn}>\mathrm{Fe}>\mathrm{Zn}>\mathrm{B}>\mathrm{Cu}$. Essa ordem dos teores dos nutrientes pode variar em funçáo do clone, da fase fenológica que a planta se encontra, das condiçóes edafoclimáticas e das práticas de manejo adotadas no seringal (Malavolta et al. 1997).

\section{CONCLUSÕES}

Os teores dos nutrientes $\mathrm{N}, \mathrm{P}, \mathrm{K}, \mathrm{S}$, Cu e $\mathrm{Zn}$ reduziram com o desenvolvimento foliar da seringueira. Por outro lado, os teores de $\mathrm{Ca}, \mathrm{Mg}, \mathrm{B}, \mathrm{Fe}$ e $\mathrm{Mn}$ aumentaram, sendo significativamente inferiores nas folhas jovens.

A redistribuiçẫo de nutrientes em folhas de seringueira é maior para os elementos $\mathrm{N}, \mathrm{P}, \mathrm{K}, \mathrm{S}$ e Cu.

A ordem relativa do teor de macronutrientes nas folhas da seringueira encontrada foi: $\mathrm{N}>\mathrm{K}>\mathrm{Ca}>\mathrm{Mg} \geq \mathrm{S}>\mathrm{P}$ e, para micronutrientes, a ordem relativa observada foi: $\mathrm{Mn}>\mathrm{Fe}>\mathrm{Zn}>\mathrm{B}>\mathrm{Cu}$.

\section{AGRADECIMENTOS}

Os autores agradecem ao Conselho Nacional de Desenvolvimento Nacional de Desenvolvimento Científico e Tecnológico $(\mathrm{CNPq})$ as bolsas de doutorado e de iniciação científica e o auxílio financeiro.

\section{BIBLIOGRAFIA CITADA}

Amarante, C.B.; Muller, R.C.S.; Dantas, K.G.F.; Alves, C.N.; Muller, A.H.; Palheta, D.C. 2010. Composição química e valor nutricional para grandes herbívoros das folhas e frutos de aninga (Montrichardia linifera, Araceae). Acta Amazonica, 40: 729-736.

Attiwill, P.M.; Guthrie, H.B.; Leuning, R. 1978. Nutrient cycling in a Eucalyptus oblique (L'Hérit) forest. I. Litter production and nutrient return. Australian Journal of Botany, 26: 79-91.

Bataglia, O.C.; Cardoso, M.; Carretero, M.V. 1988. Situação nutricional de seringais produtivos no Estado de Sáo Paulo. Bragantia, 47: 109-123.

Bataglia, O.C.; Santos, W.R.; Gonçalves, P.S.; Segnini Junior, I.; Cardoso, M. 1999. Efeito da adubação NPK sobre o período de imaturidade da seringueira. Bragantia, 58: 363-374.

Caldeira, M. V. W.; Schumacher, M. V.; Pereira, J. C.; Della-Flora, J. B.; Santos, E. M. 1999. Concentração e redistribuição de nutrientes nas folhas e no folhedo em um povoamento de Acácia mearnsii de Wild no Rio Grande do Sul. Ciência Florestal, 9: 19-24. 
Caldeira, M.V.W.; Schumacher, M.V.; Tedesco, N.; Santos, E. M. 2000. Ciclagem de nutrientes em Acacia mearnsii de Wild. V. quantificaçáo do conteúdo de nutrientes na biomassa aérea de Acacia mearnsii de Wild. procedência australiana. Revista Ciência Rural, 30: 977-982.

Cantarutti, R.B.; Barros, N.F.; Martinez, H.E. P.; Novais, R.F. 2007. XIII - Avaliação da fertilização do solo e recomendação de fertilizantes, p. 769-850. In: Novais, R.F.; Alvarez V.; V.H.; Barros, N.F.; Fontes, R.L.F.; Cantarutti, R.B.; Neves, J.C.L. Fertilidade do solo. Sociedade Brasileira de Ciência do Solo, Viçosa, Minas Gerais.

Empresa Brasileira de Pesquisa Agropecuária (Embrapa). 1999. Manual de análises quimicas de solos, plantas e fertilizantes. Embrapa Comunicação para transferência de tecnologia, Brasília, Distrito Federal. 212 pp.

Garcia, N.C.P.; Pereira, A.V.; Lima, P.C.; Salgado, L.T.; Carvalho, J.G.; Brito, S.A.; Carmo, C.A.F.S. 1999. Seringueira, p. 317-322. In: Comissão de fertilidade do solo do Estado de Minas Gerais. Recomendação para o uso de corretivos e fertilizantes em Minas Gerais: 5a aproximação. Viçosa, Minas Gerais.

Gonçalves, P.S., Bataglia, O.C.; Ortolani, A.A.; Fonseca, F.S. 2001. Manual de Heveicultura para o estado de São Paulo. Instituto Agronômico de Campinas/Fundação Instituto Agronômico de Campinas, Campinas, São Paulo. 78pp. (Boletim Técnico, 189).

Hallé, F.; Oldeman, R.A.; Tomlinson, P.B. 1978. Tropical trees and forest. Springer-Verlag, Berlim, Germany. $441 \mathrm{pp}$.

Lusk, C.H.; Matus, F.; Moreno-Chacón, M.; Saldaña, A.; JiménezCastillo, M. 2003. Seasonal variation in leaf litter nutrient concentrations of valdivian rainforest trees. Gayana Botánica. 60: 35-39.

Magalhães, L.M.S.; Blum, W.E.H. 1999. Concentration and distribution of nutrients in leaves of forest species, in eastern Amazonia. Floresta e Ambiente, 6: 127-137.

Malavolta, E.; Vitti, G.C.; Oliveira, S.A. 1997. Avaliação do estado nutricional das plantas: princípios e aplicaçóes. 2. ed. Potafos, Piracicaba, São Paulo. 319 pp.

Miguel, A.A.; Oliveira, L.E.M.; Cairo, P.A.R.; Oliveira, D. M. 2007. Photosynthetic behaviour during the leaf ontogeny of rubber tree clones [Hevea brasiliensis (Wild. ex. Adr. de Juss.) Muell. Arg.], in Lavras, MG. Ciência e Agrotecnologia, 31: 91-97.

Murbach, M.R.; Boaretto, A.E.; Muraoka, T.; Souza, E.C.A. 2003. Nutrient cycling in a RRIM 600 clone rubber plantation. Scientia Agricola, 60: 353-357.
Piatek, K.B.; Allen, H.L. 2000. Site preparation effects on foliar N and P use, retranslocation, and transfer to litter in 15-year-old Pinus taeda. Forestry Ecology Management, 129: 143-152.

Pilau, F.G.; Marin, F.R.; Camargo, M.B.P.; Assad, E.D.; Pinto, H.S.; Barbarisi, B.F. 2007. Zoneamento agroclimático da heveicultura para as regióes Sudeste e Centro-Oeste do Brasil. Revista Brasileira de Agrometeorologia, 15: 161-168.

Raij, B. van; Cantarella, H.; Quaggio, J.A.; Furlani, A.M.C. 1997. Recomendaçōes de adubação e calagem para o Estado de Sáo Paulo. 2 ed. Instituto Agronômico de Campinas/Fundação Instituto Agronômico de Campinas, Campinas, São Paulo. 285 pp. (Boletim Técnico, 100).

Reis, E.L.; Chepote, R.E.S. 2008. Solos e nutrição da seringueira. p. 251-310. In: Alvarenga, A. de P.; Carmo, C.A.F.S. Seringueira. Empresa de Pesquisa Agropecuária de Minas Gerais (EPAMIG), Viçosa, Minas Gerais.

Rodrigues, M.R.L.; Neves, C.S.V.L.; Silva, A.C.; Santos, A.R.; Paiva, A.V.; Mello, S.L.M. 2000. Concentração e redistribuição de nutrientes em folhas de Hevea brasiliensis e Pinus oocarpa. Semina: Ciências Agrárias, 21: 61-66.

Roque, C. G.; Prado, R. M.; Natale, W.; Beutler, A.N.; Centurion, J. F. 2004. Estado nutricional e produtividade da seringueira em solo com calcário aplicado superficialmente. Pesquisa Agropecuária Brasileira, 39: 485-490.

Santos, A.B.; Fageria, N.K.; Zimmermann, F.J.P. 2002. Atributos químicos do solo afetado pelo manejo da água e do fertilizante potássico na cultura de arroz irrigado. Revista Brasileira de Engenharia Agricola e Ambiental, 6: 12-16.

Silva, A.C.; Santos, A.R.; Paiva, A.V. 1998. Translocação de nutrientes em folhas de Hevea brasiliensis (clone) e em acículas de Pinus oocarpa. Revista da Universidade de Alfenas, 4: 11-18.

Shorrocks, V.M. 1965. Mineral nutrition, growth and nutrient cycle of Hevea brasiliensis: I. growth and nutrient content. Journal of the Rubber Research Institute of Malasia, 19: 1-8.

Shorrocks, V.M. 1979. Deficiências minerais em Hevea e plantas de cobertura associadas. Superintendência da Borracha, Brasília, Distrito Federal. 76 pp.

Vieira, M.; Schumacher, M.V. 2009. Concentração e retranslocação de nutrientes em acículas de Pinus taeda L. Ciência Florestal, 19: 375-382.

Virgens Filho, A.C.; Moreira, A.; Castro, P.R.C. 2003. Características físicas e químicas do látex e crescimento da seringueira em função da calagem e da adubação NPK em dois sistemas de explotaçáo. Ciência e Agrotecnologia, 27: 1237-1245.

Recebido em: 15/09/2011

Aceito em: 30/11/2011 
